\title{
Revisiting the relationship between nurse staffing and quality of care in nursing homes: An instrumental variables approach
}

\author{
HAIZHEN LIN ${ }^{*}$
}

\begin{abstract}
This paper revisits the relationship between nurse staffing and quality of care in nursing homes using an instrumental variables approach. Most prior studies rely on cross-sectional evidence, which renders causal inference problematic and policy recommendations inappropriate. We exploit legislation changes regarding minimum staffing requirements in eight states between 2000 and 2001 as exogenous shocks to nurse staffing levels. We find that registered nurse staffing has a large and significant impact on quality of care, and that there is no evidence of a significant association between nurse aide staffing and quality of care. A comparison of the IV estimation to the OLS estimation of the first-difference model suggests that ignoring endogeneity would lead to an underestimation of how nurse staffing affects quality of care in nursing homes.
\end{abstract}

Keywords: Nurse Staffing, Quality of Care, Minimum Staffing Requirements, Instrumental Variables

JEL: I10, I18

\footnotetext{
${ }^{*}$ Department of Business Economics and Public Policy, Kelley School of Business, Indiana University, 1309 East Tenth St., Bloomington, IN 47405 USA. Email: hzlin@indiana.edu. I would like to thank the Editor, two anonymous referees, John Bowblis, Seth Freedman, Marty Gaynor, Ginger Jin, Tamara Konetzka, Susan Lu, Dmitry Lubensky, Jeffrey Prince, Nathan Wilson, Xueyan Zhao, and participants at the $11^{\text {th }}$ International Industrial Organization Conference for their helpful discussions and comments. All errors are my own.
} 


\section{Introduction}

Considerable research has been devoted to examining the relationship between nurse staffing and quality of care in nursing homes (see Bostick et al. 2006 and Collier and Harrington 2008 for a review). Understanding this relationship is crucial for guiding policy interventions in order to improve quality of care and maintain cost efficiency. The past decade has seen an increase in calls to mandate minimum staffing requirements as a policy instrument to help solve the problem of quality deterioration in nursing homes nationwide (Institute of Medicine 1986; US Office of the Inspector General 1999; US General Accounting Office 2003; US Government Accountability Office 2007, 2009a, b). By 2010, 41 states, including Washington D.C., had implemented minimum staffing mandates (Harrington 2010).

Despite the large amount of literature on nurse staffing and the tremendous advocacy aimed at increasing minimum staffing requirements, existing studies have not yet reached definitive conclusions on how nurse staffing affects quality of care. For example, a large number of studies find that increases in registered nurse (RN) staffing improve health outcomes as measured by an array of quality indicators (e.g., Cohen and Spector 1996; Castle 2000; Harrington, Zimmerman, et al. 2000; Zhang and Grabowski 2004; Castle and Myers 2006; Decker 2006; Castle and Anderson 2011). Other studies, however, find no evidence to support such a direct relationship (e.g., Zinn et al. 1993; Porell et al. 1998; Intrator et al. 1999; Arling et al. 2007). Still other studies, including a well-designed study by Zimmerman et al. (2002), find some evidence of a negative association between RN staffing and quality of care. Research on the staffing of other types of nurses, such as licensed nurses (LNs) and nurse aids (NAs), is even more mixed (e.g., Cohen and Spector 1996; Castle 2000; Harrington, Zimmerman, et al. 2000; Castle and Myers 2006).

The lack of conclusive findings in the existing literature is not surprising. Most prior studies rely on cross-sectional evidence, which renders causal inference problematic and policy recommendations inappropriate. One threat to causal inference is omitted variable bias. It is likely that nursing homes with a higher level of staffing also have relatively higher levels of other inputs that affect quality of care, such as advanced medical equipment and efficient care management. Cross-sectional analyses lacking controls 
for these factors would lead to overestimates of the effect of nurse staffing on quality of care. Another threat involves endogeneity between staffing and quality of care. As Konetzka, Stearns, and Park (2008) show, staffing decisions are inherently endogenous. Nursing homes make structural decisions about staffing and quality of care subject to a set of constraints such as regulation, limited budget, and patient case mix. For example, a higher level of staffing might reflect an increased acuity level on the part of patients. Since patient case mix is difficult to control, one might expect an underestimate of the association between nurse staffing and quality of care. Analysis using longitudinal data has the advantage of accounting for time-invariant unobserved heterogeneity. However, the identification issue remains if there is time-variant unobserved heterogeneity that complicates the causal relationship between nurse staffing and quality of care.

To establish a causal relationship between nurse staffing and quality of care, this paper takes advantage of legislation changes regarding minimum staffing requirements, which we argue serve as exogenous shocks to nurse staffing levels. During 2000 and 2001, eight states (with separate requirements for RN and NA staffing) altered their mandates, which significantly impacted RN and NA staffing levels in nursing homes in those states. These legislation changes provide a great opportunity for examining the causal relationship between nurse staffing and quality of care using an IV approach. ${ }^{1}$ Our identification relies on the assumption that changes in minimum staffing requirements affect quality of care only through nurse staffing. We argue that this assumption is likely valid given the crucial roles that nurses play in nursing home care production. We also provide additional evidence in support of the exclusion restriction of our IV approach through an empirical examination of possibilities for input substitution between labor and material and through an over-identification test. Furthermore, we address the complications caused by the implementation in 2003 of tort legislation changes in three states, which could potentially threaten our identification.

\footnotetext{
${ }^{1}$ The construction of our instrumental variables follows the idea that the extent to which a nursing home changes its staffing levels correlates with its initial distance from the newly imposed standards. More specifically, we create two distance variables for RN and NA staffing. We also include their squared terms and an interaction term of the two distance variables. We provide more details in Section 3C.
} 
Using panel data from the federal On-Line Survey Certification and Reporting System (OSCAR), we find that RN staffing has a large and significant impact on quality of care, as measured by the count of deficiencies and a score measure that accounts for differentials in the scope and severity of violation for each deficiency. ${ }^{2}$ More specifically, we find that increasing RN staffing by 0.3 hours per resident day (one standard deviation in the data) increases quality by more than 16 percent, which is equivalent to lowering the number of deficiencies from the average of 7.4 in the data to 6.2. We also find that NA staffing does not have a significant impact on quality of care. Our IV estimation of the first-difference model contrasts significantly with the OLS estimation, which is likely prone to bias due to time-variant unobserved heterogeneity. Our results are robust to alternative quality measures, the inclusion of a third nurse type (licensed practical nurse, LPN), a nonlinear relationship between nurse staffing and quality of care, alternative choices of study years, and alternative selections of states for analysis.

This paper contributes to the large amount of literature on the relationship between nurse staffing and quality of care in nursing homes. ${ }^{3}$ To the best of our knowledge, most of the existing literature is noncausal. One important exception is a study by Konetzka, Stearns, and Park (2008). They utilize the introduction of a prospective payment system for Medicare in nursing homes in 1998 to serve as an exogenous financial shock to RN staffing. Using data from five states between 1997 and 2000, they find that higher RN staffing reduces adverse outcomes including pressure sores and urinary tract infections. Another exception is a paper by Zhang and Grabowski (2004), which exploits the establishment of federal minimum staffing mandates as a result of the passage of the Nursing Home Reform Act (NHRA) in 1987. This paper finds a positive association between RN staffing and quality of care, but only for cases in which nursing homes had particularly deficient staffing prior to the NHRA. Our paper differs from these two studies in several important ways. First, our identification exploits policy changes at the state instead of the national level, which enables us to produce a more precise estimation of the association between

\footnotetext{
${ }^{2}$ Quality measures using data on deficiency have been widely used in the literature. See Section 3B for more discussion. Alternative quality measures based on patient outcomes have delivered consistent results, which are covered in Section $5 B$.

${ }^{3}$ Some related studies directly examine the policy impact of imposing minimum staffing requirements in nursing homes, such as Park and Stearns (2009) and Matsudaira (2012).
} 
staffing and quality of care. Moreover, the richness in state policy variation allows us to conduct additional tests in support of the validity of the exclusion restriction of our IV approach, which is not used by Zhang and Grabowski (2004) and remains untested by Konetzka, Stearns, and Park (2008). Second, we explicitly study RN and NA staffing (and LPN staffing in a supplemental analysis) and separately identify their impact on quality of care. Lastly, we provide additional evidence by using deficiencies as proxies for overall quality of care.

Additionally, this paper closely relates to the literature on hospital nurse staffing and quality of care (e.g., Aiken et al. 2002; Kovner et al. 2002; Needleman et al. 2002; Mark et al. 2004; Blegen et al. 2011; Needleman et al. 2011). Within this large literature, the following two studies using hospital discharge data from California are worth noting. Evans and Kim (2006) exploit variation in Friday/Saturday admission to hospitals to identify whether a large shock of increased admission leads to adverse outcomes for patients admitted on Thursdays. They find evidence of some small effects. Cook, Gaynor, Stephens, and Taylor (2012) directly examine the association between hospital nurse staffing and patient outcomes using the failure to rescue rate and rate of decubitus ulcers. They find no evidence of a causal impact of nurse staffing on quality of care. Note that their identification relies on the mandates for minimum nurse staffing levels in California implemented in 2004. Our empirical strategies adapt those used in Cook, Gaynor, Stephens, and Taylor (2012).

\section{Background and Study Design}

\section{A. Roles of Different Types of Nurses and Their Potential Impact on Quality of Care}

Following the literature, we distinguish between three types of nurses: registered nurses (RNs), licensed practical nurses (LPNs), and nurse aids (NAs). We also refer to licensed nurses (LNs) as the combination of RNs and LPNs. RNs include registered nurses and directors of nursing. RNs mainly play supervisory roles: they supervise other nurses, assess residents' health conditions, develop treatment plans, and administer medications. RNs are also responsible for assigning nurses’ work schedules. LPNs primarily carry out medication management and tasks such as taking patients’ vital signs (e.g., blood 
pressure and temperature). NAs include certified nursing assistants and nursing assistants, who provide direct nursing care to help residents with daily living activities such as bathing, dressing, using the toilet, and taking medication.

Conceptually, RN staffing is vital to the quality of care provided in nursing homes. RNs' clinical knowledge, care coordination, and professional oversight make them likely to be crucial factors in determining the quality of nursing home care (Castle and Anderson 2011). NAs also appear essential given that they deliver 80-90 percent of direct care to patients (Institute of Medicine 1996). LPNs might have a lesser influence on quality of care given the narrow range of duties that they conduct as compared to RNs and NAs (Castle and Anderson 2011). However, their roles might be equally important insofar as LPNs supervise NAs and are better trained and more knowledgeable regarding resident care than NAs.

Given the important and discernible role that each type of nurse plays in nursing home care production, existing studies as well as several government reports have continuingly called for the imposition of more stringent minimum staffing mandates (e.g., Harrington, Kovner, et al. 2000; Abt 2001; Zhang et al. 2006). ${ }^{4}$ However, existing recommendations have had to be built largely upon noncausal and therefore inconclusive evidence regarding the relationship between nurse staffing and quality of care. In this study, we aim to establish a causal relationship between nurse staffing and quality of care in nursing homes by using longitudinal data and an IV approach. Our main analysis focuses on RNs and NAs; we also provide supplemental analysis on LPNs.

\section{B. Minimum Staffing Requirements in Eight States}

To identify how RNs and NAs affect quality of care, we exploit policy changes regarding minimum staffing requirements for both RNs and NAs. Legislation imposing new mandates would lead nursing homes to adjust nurse staffing levels to comply, providing a great opportunity for establishing a causal

\footnotetext{
${ }^{4}$ The Hartford Panel, a panel of interdisciplinary health-care experts, proposes a minimum staffing level of 4.55 HPRD for direct-care staffing and at least one RN on duty 24 hours per day, regardless of facility size (Harrington, Kovner, et al. 2000). A CMS study by Kramer and Fish (2001) identifies a direct-care threshold of 4.1 HPRD, including 0.75 HPRD for RNs, below which residents are at substantially higher risk. Another CMS study by Schnelle et al. (2001) concludes that a minimum of 2.8 to 3.2 HPRD for NA staffing is necessary to ensure quality of care.
} 
relationship between nurse staffing and quality of care. Federal legislation on nurse staffing traces back to the introduction of the Federal Nursing Home Reform Act, which was part of the Omnibus Budget Reconciliation Act (OBRA) of 1987. The OBRA sets a minimum staffing level of 0.30 hours per resident day (HPRD) for LNs (and 0.08 HPRD for RNs). No federal regulation has been adopted for NAs. Since the introduction of the OBRA, a large number of states have imposed additional requirements on minimum staffing for LNs and/or NAs (or as a combined mandate for LNs and NAs), which a Medicareand/or Medicaid-certified nursing home must meet to be certified and to be reimbursed for its Medicaid and Medicare patients.

In this study, we choose eight states (Arkansas, California, Delaware, Florida, Iowa, Maine, Mississippi, and Ohio) that satisfy the following criteria: (a) imposed separate mandates for RNs (or LNs) and NAs, and (b) experienced legislation changes regarding minimum staffing requirements in 2000 or 2001. ${ }^{5}$ The first criterion is important as we rely on exogenous changes in staffing for both RNs and NAs to identify the impact of each nurse type. The second criterion is chosen primarily because most legislation changes took place in 2000 or $2001{ }^{6}$ Since our data spans from 1996 to 2003, focusing on policy changes that occurred in 2000 or 2001 allows us to (a) have enough years' observation in the preimplementation period to construct both the instrumental variables (using years 1996-1998) and the initial staffing conditions (using year 1999) and (b) have at least a two-year period following implementation in which nursing homes can adjust to new mandates.

Minimum staffing requirements vary considerably across states and over time. ${ }^{7}$ We follow a method proposed by Harrington (2001) to convert standards to a uniform format—nursing hours per resident day

\footnotetext{
${ }^{5}$ Data on statutes and regulations have been collected from the previous literature, with the primary data sources including Harrington (2001, 2008), Tilly et al. (2003), and Mueller et al. (2006). In case of a disagreement about a specific policy, relevant state agencies have been contacted for clarification.

${ }^{6}$ Among the states that satisfy the first criterion (with separate mandates for LNs and NAs), no legislation changes occurred after 2001 in our data. Before 2000, only two states had experienced changes in policies: Wisconsin in 1998 and South Carolina in 1999.

${ }^{7}$ State regulation varies in the following three major ways. First, minimum staffing requirements are established in various forms. For example, California requires a total of 3.2 nursing hours per resident day, while Maine maintains staff-to-resident ratios of 1 to 5 during the day, 1 to 10 in the evening, and 1 to 15 at night. Second, standards might
} 
for a 100-bed nursing facility ${ }^{8}$-in order to compare the stringency of minimum staffing standards across states. ${ }^{9}$ The converted standards are reported in Table 1 for the eight states examined in this study.

We observe a large increase in minimum staffing requirements for RNs and NAs in 2000 and 2001. The legislation reported for 1996 represents the initial legislation prior to policy changes. Note that several states (Arkansas, Delaware, and Florida) experienced multiple legislation changes or staffing phase-in periods. For example, before 2001, Arkansas had no state legislation regarding minimum staffing requirements, so it followed the federal regulation (0.3HPRD for LNs and 0.08 HPRD for RNs). In 2001, Arkansas implemented legislation that mandated a minimum of 0.48 HPRD for LNs, 0.16 HPRD for RNs, and 2.44 HPRD for NAs, acting as the first step of phased-in increased staffing. The legislation was aimed at increasing NA staffing to 2.64 HPRD by 2003.

\section{Minimum Staffing Requirements and Nurse Staffing}

We argue that changes in minimum staffing requirements serve as exogenous shocks to nurse staffing levels. It is important to note that only mandates that are binding for a large fraction of nursing homes can potentially create enough variation in nurse staffing levels. If newly imposed standards are not binding for a majority of nursing homes, one would expect no significant changes in staffing levels following the implementation of legislation.

To see whether the newly imposed standards are binding, we compare nurse staffing levels (prior to policy changes) for each type of nurse to the state's newly imposed standards. We find that LN standards are not binding for the majority of homes in the data. Specifically, more than 90 percent of nursing homes already had LN staffing levels higher than the new standards. As a result, the newly imposed LN standards were not expected to have a large impact on nurse staffing levels. However, for RN and NA

vary depending on facility size. Third, there is some variation across states regarding the extent to which LPNs can substitute for RNs when LN standards are specified.

${ }^{8}$ Minimum staffing requirements might vary in terms of facility size, so we choose a 100-bed capacity to standardize the regulation.

${ }^{9}$ For example, a ratio of 1:10 nurse per resident is converted to 8 hours (for 1 full-time nurse working 8 hours per day) and divided by the number of residents (10) to determine that the total is 0.8 HPRD. These ratios are added for all three shifts during a day. A more detailed discussion of the conversion can be found in Harrington (2001). 
standards, we find that prior to the standards' implementation, more than 32 and 49 percent of nursing homes were below the newly imposed mandates, suggesting that a large fraction of nursing homes had to increase their RN and NA staffing to comply. Based on the above observations, we use minimum staffing standards on RNs and NAs to construct instrumental variables for our empirical analysis, with the details covered in Section 3C.

We hypothesize that binding nursing homes will increase staffing levels in order to comply. Regarding nonbinding nursing homes, it is ex ante ambiguous whether imposing staffing mandates will lead to an increase or a decrease of staffing levels. On one hand, nonbinding nursing homes might reduce staffing levels given that binding homes are forced to hire more nurses, which might lead to a rise in nurse wages. On the other hand, nonbinding homes might be incentivized to hire more nurses to differentiate themselves from binding ones, which have increased their staffing levels in the wake of staffing mandates. Depending on the extent of these two counteracting effects, the equilibrium employment for nonbinding nursing homes could be below or above their initial staffing levels.

An examination of the data patterns in staffing levels (separately for binding and nonbinding nursing homes ${ }^{10}$ ) prior to and following policy changes has illuminated several interesting points. ${ }^{11}$ First, there is evidence that binding nursing homes increased NA staffing more than nonbinding ones, resulting in less variation in NA staffing following an increase in minimum staffing requirements. For example, in California, binding nursing homes increased NA staffing from about 2.02 to 2.49 from 1999 to 2003; meanwhile, nonbinding homes slightly increased NA staffing from about 2.63 to 2.75. Second, RN (and LN) staffing levels exhibit differential trends for binding and nonbinding nursing homes in the postimplementation period. For nonbinding nursing homes, RN (and LN) staffing observe a decreasing trend over time. For example, average RN staffing for nonbinding homes decreased from 0.50 in 1999 to 0.40

\footnotetext{
${ }^{10}$ A nursing home is considered to be binding for RN (NA) mandates if its initial RN (NA) staffing prior to policy changes was lower than that required by the newly imposed standards. The initial staffing levels are calculated separately for RNs and NAs using the median of corresponding staffing levels between 1996 and 1998 throughout the paper. Using alternative methods, such as the year 1998, delivers similar results.

${ }^{11}$ A regression analysis of how staffing mandates affect nurse staffing levels is performed. These results are consistent with the observed data patterns, which we report in Section 6B where we discuss the policy implications of imposing staffing mandates.
} 
in 2003 for Ohio and from 0.61 to 0.54 during the same time period for California. In contrast, for binding nursing homes, RN (and LN) staffing generally see a very mild increase over time.

The above observations suggest that nursing homes, especially binding ones, change their staffing levels in response to staffing mandates, confirming that regulatory changes to minimum staffing requirements serve as exogenous shocks to nurse staffing and thereby allow us to identify the causal relationship between staffing and quality of care. In addition, the observed data patterns indicate that staffing mandates could have heterogeneous effects on the labor market depending on the type of nurses under consideration, highlighting the importance of examining the relationship between quality and nurse staffing separately for RNs and NAs.

\section{Data and Summary Statistics}

\section{A. Data Source and Sample Selection}

Our primary data source is the federal On-Line Survey Certification and Reporting System (OSCAR). OSCAR is based on a federal annual survey conducted by state licensure and certification agencies as part of the Medicare and/or Medicaid certification process and to verify the compliance of nursing homes with all federal Medicare and Medicaid quality and performance standards. OSCAR covers all Medicare- or Medicaid-certified nursing homes and accounts for approximately 96 percent of all nursing facilities in the U.S. We supplement OSCAR with data on market characteristics from the 2004 Area Resource File (ARF), the Centers for Medicare \& Medicaid Services, and the most recent population census.

The sample included in our main analysis comes from OSCAR 1999 and 2003. ${ }^{12}$ We have selected 1999 because it immediately precedes the regulatory changes that took place in 2000 and 2001; we have selected 2003 in order to allow sufficient time (at least two years) for nursing homes to adjust to the new

\footnotetext{
${ }^{12}$ The survey is conducted every 9-15 months, so there are cases in which a nursing home will not be surveyed in a particular year. In these cases, we use the value of the neighbor year to fill in the missing data. For example, if a nursing home was not surveyed in 1999, we use its 1998 survey instead. If a nursing home was not surveyed in 2003, we use its 2004 survey.
} 
mandates. Our sample excludes skilled nursing facilities as they typically provide short-term post-acute care and thus require a much higher level of staffing compared to the remaining nursing homes.

\section{B. Key Variables}

We use OSCAR to construct key variables of our interest, that is, nurse staffing levels and quality of care, at the nursing home level. Regarding nurse staffing, each facility reports the number of full-time equivalent hours (FTE, including full-time, part-time, and contract nurses) for each type of nurse for a 2week period prior to each survey date. The FTE is then converted to nurse staffing hours per resident day using the following formula: (FTE*70)/(14*number of total patients). ${ }^{13}$ We calculate nurse staffing separately for RN (including registered nurse and director of nursing), LPN, LN (RN plus LPN), and NA (including nurse aid, nurse-aid trained, and medication nurse aid). Note that staffing information in OSCAR is self-reported. Although inspectors review this information during each survey visit, no formal audit is performed to ensure data accuracy (Harrington, Zimmerman, et al. 2000). To minimize measurement errors due to self-reporting, we drop observations that reported staffing (separately for RN, LN, and NA) of more than three standard deviations above the mean or zero staffing, following Bowblis (2011).

We draw quality information using data on deficiencies from OSCAR, which is considered the greatest source of reliable and accurate information regarding quality of care in U.S. nursing homes (Harrington, Zimmerman, et al. 2000). ${ }^{14}$ Surveyors issue deficiencies to facilities as part of the federal survey process. There are a total of 185 tags (in 15 major areas) to cite, each of which corresponds to one criterion related to the quality of nursing home care (Harrington et al. 2005). If a nursing home fails to meet or violates one particular criterion, a corresponding deficiency citation will be issued. Deficiencies represent surveyors’ assessments about quality problems that exist in nursing homes.

\footnotetext{
${ }^{13}$ This assumes that one full-time equivalent nurse works 70 hours in two weeks. This formula has been used in most of the existing studies, such as Abt Associates (2001) and Konetzka, Stearns, and Park (2008).

${ }^{14}$ Many studies use deficiencies as the measure for quality, such as Nyman (1985, 1988, 1989), Grabowski (2001a, 2004), Mullan and Harrington (2001), O'Neil et al. (2003), and Wiener et al. (2007).
} 
Two measures are used to provide a quantitative indicator of quality. The first measure is the count of total deficiencies, and the second is a score measure that sums up numeric scores for each deficiency. Effective in July 1995, an alphabetic score (from A to L) is given to each deficiency based on the combination of the deficiency's scope and severity indicator. We follow Matthews-Martin (2003) in assigning each letter a numeric score. For example, a deficiency with a scope and severity of D receives a score of five, whereas a deficiency with a scope and severity of $\mathrm{K}$ receives a score of 45 . The score measure of deficiencies takes into account differentials in the scope and severity of each deficiency.

In addition to total deficiencies, we also follow Harrington, Zimmerman, et al. (2000) in assigning each deficiency into one of three distinct categories: (a) quality of care, (b) quality of life, and (c) other. ${ }^{15}$ We expect that nurse staffing directly relates to quality of care and quality of life. It is not clear whether nurse staffing should have a direct impact on other deficiencies, because this category does not directly relate to direct-care nurse staffing (Harrington, Zimmerman, et al. 2000).

The abovementioned quality measures are based on data on deficiencies. To extend our analyses, we adopt another two measures based on patient outcomes: the fraction of residents with pressure sores and the fraction with contractures. A pressure sore (or bedsore) is an injury to the skin and underlying tissue caused by constant pressure and/or lack of blood supply, for example, by lying or sitting stationary in the same position. A contracture is a shortening of the muscles or tendon, usually associated with non-use of a joint. These two variables are particularly good outcome measures for quality because they are preventable and treatable conditions, regardless of the underlying health of residents (Grabowski 2001b; Bowblis, Meng, and Hyer 2012).

\footnotetext{
${ }^{15}$ Quality of care includes 72 specific items in the following federal survey categories: resident assessment (F271F285), quality of care (F309-F33), nursing services (F353-F354), dietary services (F360-F372), physician services (F385-F390), rehabilitative services (F406-F407), dental services (F411-F412), pharmacy services, and infection control (F425-F432 and F441-F445). The quality of life category includes 77 specific items on resident's rights (F151-F177); admission, transfer, and discharge rights (F201-F208); resident behavior and facility practices (F221F226); quality of life (F240-F258); and physical environment (F454-F469). The "other" category includes administration, laboratory services, and other activities (F490-F522).
} 


\section{Instrumental variables}

We construct our instrumental variables by exploiting changes in minimum staffing requirements. As discussed in Section 2C, we find evidence that the imposition of new standards affects nurse staffing levels, especially for binding nursing homes. We expect that the extent to which a nursing home changes its staffing levels will correlate with its initial distance from the newly imposed standards. To this end, we construct two distance variables: one for RN staffing (DIST_RN) and the other for NA staffing (DIST_NA), with each defined as the difference between a nursing home’s initial nurse staffing levels and the newly imposed standards. Regarding the initial nurse staffing levels for RN and NA, we use a nursing home's corresponding median staffing levels for the years 1996 through $1998 .^{16}$ We also use other alternative measures, including staffing levels for a specific year such as 1998 or 1997, to construct the initial staffing levels for a given nursing home, with more details covered under Section 5D, which considers robustness tests.

Note that DIST is negative for binding nursing homes and positive for nonbinding ones. We adapt the identification strategies used by Cook, Gaynor, Stephens, and Taylor (2012) and also include the squared DIST and the interaction between $D I S T \_R N$ and $D I S T \_N A$. This is because there might be nonlinearity in how nursing homes respond to minimum staffing requirements based on their initial staffing levels; any adjustment to one type of nurse might also depend on the initial staffing level of the other type of nurse.

\section{Other Market Controls}

We draw market-level controls from the ARF, which collects data on population characteristics, socioeconomic features, and health-care resources. Variables used in this study include average income (log), size of the senior population (log), Medicare reimbursement rate, and Medicaid nursing home reimbursement rate. ${ }^{17}$ Since the majority of patients pay through Medicaid and Medicare, it is important

\footnotetext{
${ }^{16}$ Using the mean instead of the median to define a nursing home's initial staffing delivers similar results, which are not reported but are available upon request.

${ }^{17}$ We use the Medicare fee-for-service payment rate for Part A services as a proxy for the Medicare nursing home reimbursement rate. To collect the Medicaid nursing home reimbursement rate one has to contact each state office.
} 
to control for payment rate differentials across states and over time in examining quality of care (e.g., Gertler 1989 and Nyman 1985). We also include a wage index from the Centers for Medicare \& Medicaid Services as a control for geographic variation for nursing home labor costs.

\section{E. Summary Statistics}

We report summary statistics in Table 2. Note that the final sample for our main analysis consists of a set of 3,275 unique nursing homes, representing about $85 \%$ of the eligible observations from the eight states under this study. RN staffing averages $0.34 \mathrm{HPRD}$, exhibiting large variation as reflected by a standard deviation of 0.32. NA staffing averages 2.44 HPRD. LN staffing, which includes figures for RNs and LPNs, averages 1.10 HPRD.

Regarding measures of quality, the total number of deficiencies averages 7.37 with a standard deviation of 6.21. Note that a larger number of deficiencies is associated with a higher rate of violations of federal quality standards and therefore a lower level of quality of care. A zero deficiency signals the highest level of quality in the data. The score measure of deficiencies takes into consideration differentials in the scope and severity of each deficiency, which averages 41.06 with a standard deviation of 43.61 . If we decompose the count of total deficiencies into three categories, quality of care, quality of life, and other, they average 4.34, 2.05, and 0.50 , respectively. The patient-outcome-based quality measures have a mean of 0.07 for the prevalence of pressure sores and 0.33 for contractures. Regarding instrumental variables, $D I S T \_R N$ ranges from -0.36 to 2.41 , with a mean of 0.14 . DIST_NA has a mean of -0.30 , indicating that a large fraction of nursing homes were initially below the newly imposed standards for NAs.

\section{Empirical Model}

To identify a causal relationship between nurse staffing (separately for RN and NA) and quality of care in nursing homes, we specify our main model as follows:

Professor Nicholas Castle has kindly provided this part of the data. Note that our empirical model also controls for state-specific linear trends and our results are consistent if Medicaid reimbursement rates are excluded. 


$$
Y_{j i s t}=\beta_{0}+\beta_{1} R N_{j i s t}+\beta_{2} N A_{j i s t}+X_{i s t} \gamma+\alpha_{j}+\alpha_{t}+\eta_{s} t+\varepsilon_{j i s t}
$$

where $Y_{j i s t}$ represents one of the quality measures for nursing home $j$ at market $i$ state $s$ time $t . R N_{j i s t}$ and $N A_{j i s t}$ represent RN and NA staffing, respectively. The coefficients $\beta_{1}$ and $\beta_{2}$ are our primary research interest; they measure the extent to which an increase in nurse staffing affects quality of care. $X_{i s t}$ is the vector of variables representing market characteristics such as the elderly population and average income. $\alpha_{j}$ and $\alpha_{t}$ represent nursing home and year fixed effects, respectively. $\eta_{s} t$ is the statespecific linear trend, the inclusion of which allows our model to be robust to any arbitrary heterogeneity in the dependent variable that follows a state-specific time trend. For example, a state's increasing sensitivity to quality issues may have caused surveyors to engage in more stringent inspections and increased deficiency citations during each survey visit. Such stringent inspections would have systematically lowered the survey measure of quality.

There are two issues regarding the existence of unobserved heterogeneity that might complicate the causal relationship between nurse staffing and quality of care. The first issue relates to time-invariant unobservables, which could be controlled for by introducing nursing home fixed effects $\alpha_{j}$. To this end, we take the first-difference of equation (1) and focus on the model as follows:

$$
\Delta Y_{j i s}=\beta_{1} \Delta R N_{j i s}+\beta_{2} \Delta N A_{j i s}+\Delta X_{i s} \gamma+\Delta \alpha+\eta_{s}+\Delta \varepsilon_{j i s}
$$

The second issue is somewhat more complicated and is caused by time-variant unobservables. In this study, we take advantage of exogenous legislation changes in minimum staffing requirements and use variation in staffing requirements to construct instrumental variables to identify the causal relationship between nurse staffing and quality of care. To proceed with our estimation, we take the first difference using observations from 1999 (pre legislation change) and 2003 (post legislation change). We also conduct several robustness tests using alternative years for analysis, which we cover in more detail in Section 5D. 


\section{Results}

\section{A. Main Results Regarding Nurse Staffing and Quality of Care}

Table 3 reports the estimation results of the first-difference model using equation (2) where quality is measured by a (negative) logarithm of the count of total deficiencies for ease of interpretation of the results. Column 1 represents the OLS results, where we find both RN and NA staffing have small and insignificant impact on quality of care. As discussed earlier in the paper, the first-difference model controls for time-invariant heterogeneity, but is likely subject to bias caused by time-variant unobserved heterogeneity. Column 2 reports the results using an IV estimation of equation (2); these results differ dramatically from the OLS results. We find that increasing RN staffing by 0.3 HPRD (one standard deviation in the data) would increase quality by more than 16 percent, which is equivalent to lowering the number of deficiencies from the average of 7.4 to 6.2. We also find that NA staffing does not have a significant impact on quality of care.

To compare the OLS and IV estimations, we perform a Wu-Hausman test and reject the null hypothesis that the two staffing variables are exogenous (p-value is 0.02), suggesting that the IV estimates should be preferred. The comparison of these results also suggests that ignoring endogeneity tends to lead to an underestimation of the impact of nurse staffing.

One underlying assumption of our IV approach is that changes in minimum staffing requirements affect quality of care only through nurse staffing. However, it is possible that increasing minimum staffing requirements encourages nursing homes to reduce other inputs of nursing home care production, such as medical equipment, suggesting a potential violation of the exclusion restriction of an IV approach. ${ }^{18}$ Previous studies have found a tendency in nursing homes’ behavior toward input substitution. For example, Zinns (1993) and Cawley, Grabowski, and Hirth (2006) show that nursing homes

\footnotetext{
${ }^{18}$ According to Gertler and Waldman (1992), the cost function of a nursing home comprises labor, supplies, and capital. Gertler and Waldman (1992) argue that there are very limited substitution possibilities between labor and capital since a nursing home's capital stock mainly consists of the building, which is usually treated as a quasi-fixed factor.
} 
are more likely to substitute material-intensive methods of care for labor-intensive methods of care in markets with higher average nursing home wages.

To address the concerns of input substitution, we first argue that such nonstaffing effects of minimum staffing requirements on quality of care, if any, are likely to be small. This is because nurse staffing is arguably the most influential input and a dominant determinant in nursing home care production; costs related to nurse staffing account for the largest expense in nursing home operations (Gertler and Waldman 1992). We also expect that such nonstaffing effects are more likely to surface on a longer horizon, as opposed to a couple of years following the legislation changes during which we identify the relationship between quality of care and staffing levels in this study. In addition to the above arguments, we offer an empirical examination and find no strong evidence of material input changes in the wake of staffing mandates. In Section 6A we cover these results, along with a discussion of other possibilities of input substitution. Another potential threat to our identification is that there might be other legislation changes affecting quality of care that occur concurrently and relate to minimum staffing legislation. We specifically consider the state tort reform that took place in three states in 2003 in Section 5D.

To provide additional support for the exclusion restriction of our IV approach, we perform an overidentification test (Sargan 1958). Note that this test is feasible as the number of instrumental variables available is greater than the number of endogenous variables in our study. The Sargan-Hansen statistic is 3.155 (the p-value is 0.368 based on a Chi-squared distribution with three degrees of freedom), suggesting that the joint null hypothesis that the instruments are valid cannot be rejected.

We also show statistically that our instrumental variables are highly correlated to RN and NA staffing levels. We find that a joint $F$-test on the excluded instruments in the first stage regressions is 34.81 for RN staffing and 48.60 for NA staffing, both of which are highly significant at lower than the 
0.01 level. ${ }^{19}$ We also perform tests of weak instruments using a Cragg-Donald Wald $F$ statistic $(F=27.24)$, indicating that weak instruments are not an issue (as discussed, e.g., in Stock and Yogo 2005). ${ }^{20}$

\section{B. Alternative Quality Measures}

Column 1 of Table 4 reports the results using a score measure of deficiencies, which takes into account differentials in the scope and severity of each deficiency. These results reveal an even stronger relationship between RN staffing and quality of care. Columns 2 to 4 provide a closer examination of quality of care in different dimensions by dividing the total count of deficiencies into three different categories: (a) quality of care, (b) quality of life, and (c) other. We hypothesize that nurse staffing should have a direct impact on quality of care and quality of life. It is not straightforward ex ante how nurse staffing would affect other deficiencies, but we suspect that the impact is likely to be small and insignificant. This is because other deficiencies relate primarily to administration, on which nurses are not expected to have a direct impact (Harrington, Zimmerman, et al. 2000). Our results are consistent with our hypothesis. We find that RN staffing does increase quality in the dimensions of quality of care and quality of life. However, other deficiencies do not seem to respond to RN or NA nurse staffing.

The above quality measures are all based on deficiencies, which are considered reliable indicators for overall quality of care in nursing homes. It would be interesting to examine whether our results hold for other types of quality measures, such as patient-outcome-related measures that have been used in the literature. Columns 5 and 6 of Table 4 use the fraction of residents with bedsores and the fraction with contractures. The results are largely consistent with our main findings based on deficiency-related quality measures. More specifically, we find that a one-standard-deviation increase in RN staffing is associated

\footnotetext{
${ }^{19}$ The estimated coefficients for the five excluded instruments in the order of DIST_RN, DIST_NA, DIST_RN ${ }^{2}$, DIST_NA ${ }^{2}$, and DIST_RN_NA are $-0.236(0.025)^{* * *},-0.004(0.010), 0.068(0.017)^{* * *}, 0.005(0.005)$, and -0.036 $(0.015) * *$ for the RN staffing equation (standard errors in parentheses) and $-0.017(0.073),-0.361(0.028) * * *, 0.039$ (0.049), -0.012 (0.015), and 0.010 (0.044) for the NA staffing equation.

${ }^{20}$ The $F$ statistic should be compared to Table 1 (to bound bias) or Table 2 (to bound size of Wald tests) in Stock and Yogo (2005). In our case of five excluded instrumental variables and two endogenous variables, if one wanted to restrict the bias of the IV estimator to $5 \%$ of the OLS bias, the critical value of the first stage F-statistic is 13.97 . If one wanted Wald tests (of normal size 0.05 ) of hypotheses about the parameters to have a size of less than 0.1, the first-stage $F$-statistic should be greater than 19.45 .
} 
with a $17 \%$ decrease in the fraction of residents with pressure sores and with a $10 \%$ decrease in the fraction of residents with contractures.

\section{Licensed Practical Nurses}

Our main analysis has focused on RN and NA staffing, two categories of nurses that have been most intensively studied in the existing literature due to their importance to determining quality of care in nursing homes. In this section, we provide supplemental analysis examining a third category of nurse, the LPN, which is arguably another important input in nursing home care production. We report the results in Table 5. Column 1 directly adds LPN staffing to our main model. The IV estimation provides very similar results for RN staffing as compared to our main findings from column 2 of Table 3. In addition, we find a large effect of LPN staffing, although it is not statistically significant. Note that the IV results that include LPNs assume that all three types of nurse are endogenous. We suspect that the impact of LPN staffing is not precisely identified (with a standard error of 0.725 ) due to a lack of variation of LPN staffing within nursing homes in the data. The impact of NA staffing is small and insignificant.

Column 2 studies LN staffing, which includes both RNs and LPNs. We find a large and significant association between LN staffing and quality of care. Similar to the results of column 1, NA staffing has a small and insignificant impact on quality of care.

\section{Robustness Tests}

In this section, we offer a set of robustness tests using a (negative) logarithm of the count of deficiency citations as the measure for quality of care. The results using alternative measures, such as the summed score measure of deficiencies, are largely consistent.

The first robustness test considers a nonlinear relationship between staffing levels and quality of care. That is, after a certain threshold of nurse staffing levels, there might be diminishing returns to increasing nurse staffing, so quality of care might not continue to improve or will improve at a decreasing rate (Zhang and Grabowski 2004; Castle and Anderson 2011). Column 1 of Table 6 reports the estimation results with the inclusion of the squared RN and NA staffing levels. The estimated coefficients for both squared terms are small and insignificant, suggesting no evidence of nonlinearity in the data. The 
coefficient for RN staffing is similar to our main results, and the coefficient for NA staffing becomes negative and larger in absolute magnitude, although largely insignificant.

The second robustness test addresses the complications caused by tort legislation changes that took place in 2003 in Florida, Mississippi, and Ohio. ${ }^{21}$ Tort reform could directly impact quality of care in nursing homes. If tort legislation is related to minimum staffing regulation, one could argue that tort legislation changes might impose a threat to the exclusion restriction assumption for our identification. We address this concern in the following two ways. First, we augment our main model with a dummy variable for tort reform, which is set to one for the three states in 2003 and zero otherwise. The estimation results are reported in column 2 of Table 6. After controlling for tort legislation changes, we find consistent results regarding the relationship between nurse staffing and quality of care. Second, instead of using 2003 data that might be affected by changes in tort legislation, we use data from 2002, one year prior to the implementation of tort law changes. The results, which are presented in column 4 of Table 6 , are largely consistent and will be discussed in the following paragraph, which deals with our selection of years of study.

The next two robustness tests deal with selection of years of study. Note that we examine policy changes that occurred in 2000 and 2001. In our main specification, we use 1999 as the year prior to policy changes and 2003 as the year following those changes; we calculate the median of staffing (separately for RN and NA) of years 1996 through 1998 and use this as the baseline staffing level for a nursing home to construct the instrumental variables (i.e., the distance of the baseline staffing levels from the newly imposed standards). As a robustness test, we use RN and NA staffing levels from 1998 to calculate the instrumental variables. We report the results in column 3 of Table 6; these results are very close to our main findings. The next robustness test uses 1997 as the baseline to construct the instrumental variables; it uses 1998 as the initial year and 2002 as the year following policy changes. The results, presented in column 4, are also in line with our main findings.

\footnotetext{
${ }^{21}$ Specifically, these three states capped noneconomic damages in medical malpractice lawsuits. This new legislation took effect in September 2003 in Florida, April 2003 in Ohio, and January 2003 in Mississippi. Tort legislation data come from Ronen Avraham's Data Base of State Tort Law Reforms.
} 
The last three robustness tests consider choice of states. We first drop observations from the following three states: Florida, Idaho, and Maine. We do so because these states experienced no changes in RN staffing requirements during our study's time period (although LN staffing did change in these states). The results are reported in column 5, and are consistent with our main findings. Unsurprisingly, the impact of RN staffing becomes more precisely identified because all remaining states experienced an increase in RN staffing requirements, causing more variation in RN staffing. In the next robustness test, we drop observations from Arkansas, Delaware, and Florida, as these states experienced multiple changes in legislation during our study period. The results, reported in column 6, are also consistent with our main findings. The last robustness test adds observations from a set of 11 control states that followed federal regulation and experienced no changes in minimum staffing mandates. ${ }^{22}$ One advantage of including these control states is to control for changes in quality measures that are common between the control and treatment states absent of any policy changes. The results are again largely similar.

\section{Discussions}

\section{A. Staffing Mandates and Input Substitution}

Generally speaking, three types of inputs are used in nursing home production: capital, labor, and material. Imposing staffing mandates leads to changes in staffing levels. As a result, nursing homes might adjust other inputs to minimize the cost of production. Since there are very limited substitution possibilities for capital (Cawley, Grabowski, and Hirth 2006 and Gertler and Waldman 1992), we focus on examining possibilities of substitution between labor and material. Our analysis below finds no evidence that nursing homes systematically change material inputs as a result of staffing mandates, supporting the exclusion restriction used in our IV approach.

\footnotetext{
${ }^{22}$ These 11 states include: AL, AK, ND, NE, NH, NV, RI, SD, UT, VA, and WA. We use the same set of states as a control for our other analyses in Section 6.
} 
Since staffing mandates affect nonbinding and binding nursing homes in different ways, we expect their impact on input mix to differ, too. For nonbinding nursing homes, RN mandates result in a decrease in RN staffing. In this case, it is possible that nonbinding nursing homes increase the use of materialintensive inputs to substitute for RNs. For binding nursing homes, RN mandates increase their RN staffing so they might choose to decrease their use of material-intensive inputs. In addition, given that binding nursing homes increase their NA staffing in response to NA mandates, they might also decrease material-intensive inputs. It is important to note that increasing the use of material-intensive inputs is likely to be associated with lower quality of care (a greater risk of morbidity and mortality) in the nursing home setting, as argued by Cawley, Grabowski, and Hirth (2006).

We use two commonly used variables to measure the extent of material-intensive care: the proportion of residents in the facility with physical restraints and the proportion with catheters. These two measures have been used in other studies on factor substitution such as Zinn (1993) and Cawley, Grabowski, and Hirth (2006). ${ }^{23}$ To provide a test on input mix changes, we specifically examine whether staffing mandates have any impact on these two measures, controlling for market characteristics, time fixed effects, and nursing home fixed effects for a period between 1997 and 2003 (with standard errors clustering at state level). We also allow for differential effects for binding and nonbinding nursing homes for the reasons described above. To this end, we define a binding dummy variable separately for RN and NA mandates to indicate whether a nursing home is out of compliance (i.e., the pre-policy staffing ratio was lower than the newly implemented mandate) and control for its interaction with each policy mandate. ${ }^{24}$

We report the results in Panel A of Table 7, where columns 1 and 2 focus on the eight treatment states and columns 3 and 4 add observations from a set of 11 control states that followed the federal

\footnotetext{
${ }^{23}$ These studies argue that nursing homes face decisions over managing incontinence through regularly scheduled toileting and bladder rehabilitation (labor-intensive methods of care) or through urethral catheterization (materialintensive methods of care). Similarly, monitoring residents' behavior could be achieved by constant monitoring on the part of nurses or by physical or chemical restraints.

${ }^{24}$ The pre-policy staffing levels were calculated separately for RNs and NAs using the median of corresponding staffing levels between 1996 and 1998.
} 
staffing regulation and experienced no changes in staffing mandates over our study period. One implicit assumption is that these control states provide an estimate of the outcomes that would occur in the absence of changes in staffing mandates. Overall we find no strong evidence of input substitution as a result of staffing mandates. If anything, there is a marginally significant effect that nonbinding nursing homes decrease the use of physical restraints. Note that the effect is very small and only significant at $10 \%$ level for the specification when the control states are included.

We acknowledge the fact that there might be possibilities for other types of substitution, especially in the long run. For example, binding nursing homes might reclassify nurses who work in management (or administration) positions as RNs, or similarly, they might have RNs take charge of additional duties other than caring for patients. Due to data limitations, a test of these possibilities is not feasible in this study. However, we think the magnitude of this type of substitution is likely very limited given that that the majority of labor expenses in nursing homes are attributed to nursing care. Moreover, we believe this type of substitution, if does exist, is more likely to occur to RNs rather than NAs, so the causal effect that we identify in our model could be considered a lower bound on the true effect for increasing nurse staffing for RAs.

\section{B. Policy Implications of Quality of Care}

We find a positive and strong relationship between RN staffing and quality of care, lending support to the establishment of minimum staffing requirements for RNs. That said, it is important to note that the effect of staffing mandates on quality distribution depends on how nursing homes adjust their staffing levels in response to the new mandates. If both binding and nonbinding nursing homes increase their RN staffing in the wake of $\mathrm{RN}$ mandates, we should expect quality of care to improve. However if nonbinding nursing homes decrease their RN staffing, our results could imply that quality of care deteriorates for those nursing homes.

To provide an empirical examination of equilibrium employment, we follow the specification that we use to examine input substitution and conduct a regression of staffing levels on minimum staffing mandates. The results are reported in panel B of Table 7, where columns 5 and 6 focus on nursing homes 
from the eight states chosen in our main study and columns 7 and 8 add nursing homes from these control states. The results are largely similar, so we focus on columns 5 and 6 in discussing the results.

We find that binding nursing homes significantly increase their RN staffing ratios in response to the implementation of RN mandates. What's more interesting is that nonbinding nursing homes significantly decrease their RN staffing levels. These findings suggest that the implementation of staffing mandates leads to less variation in staffing levels for RNs and thereby results in a less dispersed quality distribution. Regarding the effect of NA mandates, there is a positive effect for binding nursing homes, and the effect is much smaller and not significant for nonbinding nursing homes. Since we do not find an association between NA staffing and quality of care, the imposition of NA mandates seems not have a direct impact on quality distribution.

\section{Staffing Mandates and Cost Implications}

In addition to how staffing mandates affect employment, another interesting outcome to examine is the equilibrium wage. Following Cawley, Grabowski, and Hirth (2006), we collect data on wages for nursing home workers from the Covered Employment and Wages Data collected by the Bureau of Labor Statistics. We identify nursing home workers by North American Industry Classification System code 623: nursing and residential care. The data provides the average annual weekly wage for nursing home workers at the state level from 1997 to 2003. Similar to Cawley, Grabowski, and Hirth (2006), we lack separate wage data for RNs and NAs, so the results should be interpreted with caution.

We conduct two regressions of nurse wages at the state-year level controlling for time fixed effects and state fixed effects: one without and one with the inclusion of the 11 comparison states. The results are again largely similar across these two specifications. ${ }^{25} \mathrm{I}$ find that imposing $\mathrm{RN}$ mandates has a statistically significant but small positive impact on nurse wages. To be more specific, a one-standarddeviation increase in RN mandates is associated with a $2 \%$ increase in wage levels. This increase in wages might be explained by an outward shift in demand for RNs in the wake of RN mandates. In

\footnotetext{
${ }^{25}$ The dependent variable is the logarithm of nurse wage and standard errors use clustering at the state level. The estimated coefficients for RN and NA are $0.058^{* *}(0.029)$ and $0.004(0.007)$ for the sample of eight states and $0.064^{* *}(0.026)$ and $0.005(0.006)$ for the sample including 11 control states.
} 
contrast, I find that NA mandates have no impact on nurse wages. Several factors might contribute to the lack of effect for NA mandates. First, NAs are low-skilled nurses and their labor market might be characterized by perfect competition, suggesting that nursing homes are able to hire more nurses at the market wage. Second, nursing homes might use non-wage amenities in recruiting NAs. Unfortunately, the data available do not permit a test.

Our preliminary analysis on wages suggests that imposing staffing mandates leads to a modest increase in costs, especially for binding nursing homes, due to a mild rise in nurse wages. We acknowledge that the wage results are inconclusive due to data limitations. The impact of mandates on labor markets, especially on nurse wages, needs to be further investigated in future work.

\section{Conclusion}

Existing literature lacks a rigorous examination of the causal relationship between nurse staffing and quality of care, which makes its results difficult to interpret and inappropriate for informing policy decisions. In this study, we take advantage of policy changes in minimum staffing requirements for RNs and NAs in order to identify a causal relationship between nurse staffing and quality of care. We find that our IV estimation of the first-difference model has delivered largely different results than the OLS estimation, suggesting that ignoring endogeneity caused by time-variant heterogeneity leads to an underestimation of the effect of nurse staffing on quality of care.

We find a strong relationship between RN staffing and quality of care, lending support to the establishment of minimum staffing requirements for RNs. ${ }^{26}$ We also find that binding and nonbinding nursing homes respond differentially to RN mandates, suggesting that binding nursing homes will experience an improvement in quality of care while nonbinding ones will see a decrease in quality. The imposition of RN mandates thus reduces quality variation in nursing homes. The net welfare effect of

\footnotetext{
${ }^{26}$ It is important to note that factors other than nurse staffing, such as nurse turnover, are likely to contribute to quality of care (Harrington and Swan 2003; Castle and Engberg 2005; Castle and Anderson 2011). Given data limitations, we cannot examine these factors.
} 
imposing staffing mandates is beyond the scope of this current study mainly because there is no analysis of demand response (to changes in quality of care and to changes in private-pay prices).

It remains an open question how the imposition of staffing mandates affects the financial performance of nursing homes. It might strengthen financials through enhanced quality of care, especially for binding nursing homes. It might also lead to deterioration in financial performance due to higher labor costs resulting from the mandates, given the current shortage of nurses nationwide. Although many states increased Medicaid nursing home reimbursement rates when they introduced staffing mandates, ${ }^{27}$ many argue that these efforts do not sufficiently offset additional incurred costs. Whether the realized increase in quality of care is cost-effective and how staffing mandates affect nursing homes' financial performance are interesting and important avenues for future research.

${ }^{27}$ For example, California increased Medi-Cal rates by approximately $\$ 2.96$ per resident day to compensate for the additional costs associated with the new staffing mandates in 2000 (Horowitz et al. 2003). 


\section{References}

Abt Associates, 2001. Report to Congress: Appropriateness of Minimum Nurse Staffing Ratios in Nursing Homes Phase II Final Report. Baltimore, MD: Centers for Medicare and Medicaid Services.

Aiken, L.H., Clarke, S.P., Sloane, D.M., Sochalski, J., Silber, J.H., 2002. Hospital Nurse Staffing and Patient Mortality, Nurse Burnout, and Job Satisfaction. Journal of American Medical Association, 288, 1987-1993.

Arling, G., Kane, R.L., Mueller, C., Bershadsky, J., Degenholtz, H.B., 2007. Nursing Effort and Quality of Care for Nursing Home Residents. The Gerontologist, 47, 672-682.

Blegen, M.A., Goode, C.J., Spetz, J., Vaughn, T., Park, S.H., 2011. Nurse Staffing Effects on Patient Outcomes: Safety-Net and Non-Safety-Net Hospitals. Medical Care, 49 (4), 406-414.

Bostick, J.E., Rantz, M.J., Flesner, M.K., Riggs, C.J., 2006. Systematic Review of Studies of Staffing and Quality in Nursing Homes. Journal of the American Medical Directors Association, 7, 366-376.

Bowblis, J.R., 2011. Staffing Ratios and Quality: An Analysis of Minimum Direct Care Staffing Requirements for Nursing Homes. Health Service Research, 46 (5), 1495-516.

Bowblis, J.R., Meng, H., Hyer, K., 2012. The Urban-Rural Disparity in Nursing Home Quality Indicators: The Case of Facility-Acquired Contractures. Health Service Research, 48 (1), 47-69.

Castle, N.G., 2000. Differences in Nursing Homes with Increasing and Decreasing Use of Physical Restraints. Medical Care 38 (12), 1154-63.

Castle, N.G., Anderson, R.A., 2011. Caregiver Staffing in Nursing Homes and Their Influence on Quality of Care: Using Dynamic Panel Estimation Methods. Medical Care, 49 (6), 545-52.

Castle, N.G., Engberg, J., 2005. Staff Turnover and Quality of Care in Nursing Homes. Medical Care, 43, 616-626.

Castle, N.G., Myers, S., 2006. Mental Health Care Deficiency Citations in Nursing Homes and Caregiver Staffing. Administration and Policy in Mental Health, 33, 215-225.

Cawley, J., Grabowski, D., Hirth, R., 2006. Factor Substitution in Nursing Homes. Journal of Health Economics, 25(2), 234-247.

Cohen, J., Spector, W., 1996. The Effect of Medicaid Reimbursement on Quality of Care in Nursing Homes. Journal of Health Economics, 15 (1), 23-48.

Collier, E., Harrington, C., 2008. Staffing Characteristics, Turnover Rates, and Quality of Resident Care in Nursing Facilities. Research in Gerontological Nursing, 1 (3), 157-170.

Cook, A., Gaynor, M., Stephens, M., Taylor, L., 2012. The Effect of a Hospital Nurse Staffing Mandate on Patient Health Outcomes: Evidence from California's Minimum Staffing Regulation, Journal of Health Economics, 31 (2), 340-8.

Decker, F.H., 2006. Nursing Staff and the Outcomes of Nursing Home Stays. Medical Care Review, 44, 812-821.

Evans, W.N., Kim, B., 2006. Patient Outcomes When Hospitals Experience a Surge in Admissions. Journal of Health Economics, 25 (2), 365-388.

Gertler, J. 1989. Subsidies, Quality, and the Regulation of Nursing Homes. Journal of Public Economics, 38(1), 33-52.

Gertler, J., Waldman, M., 1992. Quality-Adjusted Cost Functions and Policy Evaluation in the Nursing Home Industry. Journal of the Political Economy, 100, 1232-1256.

Grabowski, D., 2001a. Does an Increase in Medicaid Reimbursement Rate Improve Nursing Home Quality? Journal of Gerontology, 56B (2), S84-S93.

Grabowski, D., 2001b. Medicaid Reimbursement and the Quality of Nursing Home Care. Journal of Health Economics, 20, 549-569.

Grabowski, D., 2004. A Longitudinal Study of Medicaid Payment, Private-Pay Price and Nursing Home Quality. International Journal of Health Care Finance and Economics, 4 (1), 5-26.

Harrington, C., 2001. Nursing Home Staffing Standards in State Statutes and Regulations. University of California Working Paper. 
Harrington, C., 2008. Nursing Home Staffing Standards in State Statutes and Regulations. University of California Working Paper.

Harrington, C., 2010. Nursing Home Staffing Standards in State Statutes and Regulations. University of California Working Paper.

Harrington, C., Carrillo, H., Mercado-Scott, C., 2005. Nursing Facilities, Staffing, Residents and Facility Deficiencies, 1998 through 2004. University of California Working Paper.

Harrington, C., Kovner, C., Mezey, M., Kayser-Jones, J., Burger, S., Mohler, M., et al. 2000. Experts Recommend Minimum Nurse Staffing Standards for Nursing Facilities in the United States. The Gerontologist, 40, 5-16.

Harrington, C., Swan, J., 2003. Nursing Home Staffing, Turnover, and Case Mix. Medical Care Research and Review, 60(3), 366-392.

Harrington, C., Zimmerman, D., Karon, S.K., Robinson, J., Beutel, P., 2000. Nursing Home Staffing and Its Relationship to Deficiencies. Journal of Gerontology Series B: Psychological Science and Social Science, 55 (5), S278-87.

Horowitz, H.J., Dickey, K., Montalvo, C.C., 2003. The Financial Health of the California Nursing Home Industry. California HealthCare Foundation.

Institute of Medicine, 1986. Improving the Quality of Care in Nursing Homes. Washington, DC: National Academy Press.

Institute of Medicine, 1996. Nursing Staff in Hospitals and Nursing Homes: Is It Adequate? Washington, DC: National Academy Press.

Intrator, O., Castle, N.G., Mor, V., 1999. Facility Characteristics Associated with Hospitalization of Nursing Home Residents: Results of a National Study. Medical Care, 37 (3), 228-237

Konetzka, R.T., Stearns, S.C., Park, J., 2008. The Staffing-Outcomes Relationship in Nursing Homes. Health Services Research, 43, 1025-1042.

Kovner, C., Jones ,C., Zhang, C., Gergen, P.J., Basu, J., 2002. Nurse Staffing and Postsurgical Adverse Events: An Analysis of Administrative Data from a Sample of U.S. Hospitals, 1990-1996. Health Service Research, 37, 611-629.

Kramer, A.M., Fish, R., 2001. The Relationship between Nurse Staffing Levels and the Quality of Nursing Home Care. In U.S. Centers for Medicare \& Medicaid Services, Appropriateness of Minimum Nurse Staffing Ratios in Nursing Homes. Report to Congress, Phase II final report (Chapter 2, pp. 1-26).

Mark, B.A., Harless, D.W., McCue, M., Xu, Y., 2004. A Longitudinal Examination of Hospital Registered Nurse Staffing and Quality of Care. Health Services Research, 39 (2) 279-300.

Matsudaira, J.D., 2012. Government Regulation and the Quality of Health Care: Evidence from Minimum Staffing Legislation for Nursing Homes. Forthcoming, Journal of Human Resources.

Matthews-Martin, L. 2003. Comparing Nursing Home Quality and Performance: An Evaluation of the Basic Method in Nursing Home Ranking Systems. American Health Care Association.

Mullan, T., Harrington, C., 2001. Nursing Home Deficiencies in the United States: A Confirmatory Factor Analysis. Research on Aging, 23, 503-531.

Needleman, J., Buerhaus, P., Mattke, S., Stewart M., Zelevinsky K., 2002. Nurse-Staffing Levels and Quality of Care in Hospitals. New England Journal of Medicine, 346, 1415-1422.

Needleman, J., Buerhaus, P., Pankratz, S.H., Leibson, C.L., Stevens, S.R., Harris, M., 2011. Nurse Staffing and Inpatient Hospital Mortality. New England Journal of Medicine, 364 (11), 1037-45.

Nyman, J., 1985. Prospective and Cost-Plus Medicaid Reimbursement, Excess Medicaid Demand, and the Quality of Nursing Home Care. Journal of Health Economics, 4 (3), 237-259.

Nyman, J., 1988, Excess Demand, the Percentage of Medicaid Patients, and the Quality of Nursing Home Care. Journal of Human Resources, 23 (1), 76-92.

Nyman, J., 1989. Excess Demand, Consumer Rationality, and the Quality of Care in Regulated Nursing Homes. Health Services Research, 24 (1), 105-128.

O'Neil, C., et al., 2003. Quality of Care in Nursing Homes: An Analysis of Relationships among Profit, Quality, and Ownership. Medical Care, 41 (12), 1318-1330. 
Park, J., Stearns, S.C., 2009. Effects of State Minimum Staffing Standards on Nursing Home Staffing and Quality of Care. Health Services Research, 44 (1), 56-78.

Porell, F., Caro, F.G., Silva, A., Monane, M., 1998. A Longitudinal Analysis of Nursing Home Outcomes. Health Services Research, 33 (4), 835-65.

Sargan, J.D., 1958. The Estimation of Economic Relationships Using Instrumental Variables. Econometrica, 26, 393-415.

Schnelle, J.F., Simmons, S.F., Cretin, S., 2001. In Appropriateness of Minimum Nurse Staffing Ratios in Nursing Homes. Washington, DC: U.S. Department of Health and Human Services, Health Care Financing Administration; Minimum Nurse Aide Staffing Required to Implement Best Practice Care in Nursing Facilities, pp. 1-40. Report to Congress, Phase 2 final, chap. 3

Stock, J.H., Yogo, M., 2005. Testing for Weak Instruments in Linear IV Regression. Ch. 5 in J.H. Stock and D.W.K. Andrews (eds), Identification and Inference for Econometric Models: Essays in Honor of Thomas J. Rothenberg, Cambridge University Press.

U.S. General Accounting Office., 2003. Nursing Homes Quality: Prevalence of Serious Problems, While Declining, Reinforces Importance of Enhanced Oversight. Report to Congressional Requesters GAO-03-561.Washington, D.C.: GAO.

U.S. Government Accountability Office., 2007. Nursing Homes: Efforts to Strengthen Federal Enforcement Have Not Deterred Some Homes from Repeatedly Harming Residents. GAO-07241.Washington, D.C.: GAO.

U.S. Government Accountability Office., 2009a. CMS's Specific Focus Facility Methodology Should Better Target the Most Poorly Performing Facilities Which Tend to Be Chain Affiliated and ForProfit. GAO-09-689. Washington, D.C.: GAO.

U.S. Government Accountability Office., 2009b. Nursing Homes: Addressing the Factors Underlying Understatement of Serious Care Problems Requires Sustained CMS and State Commitment. GAO10-70. Washington, D.C.: GAO.

U.S. Office of the Inspector General, Department of Health and Human Services., 1999. Nursing Home Survey and Certification: Deficiency Trends (OEI-02-98-00331). Washington, D.C.: OIG.

Wiener, M., et al., 2007. Nursing Home Care Quality Twenty Years after the Omnibus Budget Reconciliation Act of 1987. The Henry J. Kaiser Family Foundation.

Zhang, N., et al., 2006. Minimum Nurse Staffing Ratios for Nursing Homes. Nursing Economics, 24(2), 78-85.

Zhang, X., Grabowski, D., 2004. Nursing Home Staffing and Quality under the Nursing Home Reform Act. The Gerontologist, 44, 13-23.

Zimmerman, S., Gruber-Baldini, A.L., Hebel, J.R., Sloane, P.D., Magaziner, J., 2002. Nursing Home Facility Risk Factors for Infection and Hospitalization: Importance of Registered Nurse Turnover, Administration and Social Factors. Journal of the American Geriatrics Society, 50, 1987-1995.

Zinn, J.S., Aaronson, W.E., Rosko, M.D., 1993. Variations in the Outcomes of Care Provided in Pennsylvania Nursing Homes: Facility and Environmental Correlates. Medical Care, 31(6), 475487.

Zinn, J.S., 1993. The Influence of Nursing Wage Differentials on Nursing Home Staffing and Resident Care Decisions. The Gerontologist, 33 (6), 721-729. 
Table 1: Minimum Staffing Requirements in Eight States

\begin{tabular}{|c|c|c|c|c|c|}
\hline State & Year & $\mathrm{RN}$ & $\mathrm{LN}$ & NA & Total \\
\hline Arkansas & $\begin{array}{l}1996 \\
2001 \\
2003\end{array}$ & $\begin{array}{l}0.08 \\
0.16 \\
0.16\end{array}$ & $\begin{array}{c}0.3 \\
0.48 \\
0.48\end{array}$ & $\begin{array}{c}0 \\
2.44 \\
2.64\end{array}$ & $\begin{array}{c}0.3 \\
2.92 \\
3.12\end{array}$ \\
\hline California & $\begin{array}{l}1996 \\
2000\end{array}$ & $\begin{array}{c}0.08 \\
0.3\end{array}$ & $\begin{array}{l}0.3 \\
0.3\end{array}$ & $\begin{array}{c}2.4 \\
2.96\end{array}$ & $\begin{array}{c}2.7 \\
3.26\end{array}$ \\
\hline Delaware & $\begin{array}{l}1996 \\
2001 \\
2002 \\
2003\end{array}$ & $\begin{array}{l}0.08 \\
0.32 \\
0.32 \\
0.32\end{array}$ & $\begin{array}{c}0.3 \\
0.92 \\
1.08 \\
1.2\end{array}$ & $\begin{array}{c}1.95 \\
2.08 \\
2.2 \\
2.47\end{array}$ & $\begin{array}{c}2.25 \\
3.0 \\
3.28 \\
3.67\end{array}$ \\
\hline Florida & $\begin{array}{l}1996 \\
2001 \\
2002 \\
2003\end{array}$ & $\begin{array}{l}0.08 \\
0.08 \\
0.08 \\
0.08\end{array}$ & $\begin{array}{c}0.3 \\
0.6 \\
1 \\
1\end{array}$ & $\begin{array}{c}0 \\
1.7 \\
2.3 \\
2.6\end{array}$ & $\begin{array}{l}0.3 \\
2.3 \\
3.6 \\
3.6\end{array}$ \\
\hline Iowa & $\begin{array}{l}1996 \\
2000\end{array}$ & $\begin{array}{l}0.08 \\
0.08\end{array}$ & $\begin{array}{l}0.3 \\
0.4\end{array}$ & $\begin{array}{c}0.96 \\
1.6\end{array}$ & $\begin{array}{c}1.26 \\
2.0\end{array}$ \\
\hline Maine & $\begin{array}{l}1996 \\
2001\end{array}$ & $\begin{array}{l}0.48 \\
0.48\end{array}$ & $\begin{array}{l}0.56 \\
0.56\end{array}$ & $\begin{array}{c}1.5 \\
2.34\end{array}$ & $\begin{array}{c}2.06 \\
2.9\end{array}$ \\
\hline Mississippi & $\begin{array}{l}1996 \\
2000\end{array}$ & $\begin{array}{l}0.08 \\
0.16\end{array}$ & $\begin{array}{c}0.3 \\
0.48\end{array}$ & $\begin{array}{c}1.9 \\
2.32\end{array}$ & $\begin{array}{l}2.2 \\
2.8\end{array}$ \\
\hline Ohio & $\begin{array}{l}1996 \\
2001\end{array}$ & $\begin{array}{l}0.08 \\
0.32\end{array}$ & $\begin{array}{c}0.8 \\
0.75\end{array}$ & $\begin{array}{l}1.7 \\
2.0 \\
\end{array}$ & $\begin{array}{r}2.5 \\
2.75 \\
\end{array}$ \\
\hline
\end{tabular}

Note: All standards are converted to nursing hours per resident day for a 100-bed nursing facility. The legislation reported for 1996 represents the initial legislation prior to policy changes. Total is the summation of LN and NA standards. 
Table 2: Summary Statistics

\begin{tabular}{|c|c|c|c|}
\hline Variable & Definition & Mean & Std. Dev. \\
\hline \multicolumn{4}{|l|}{ Staffing } \\
\hline RN & Registered nurses, including directors of nursing & 0.338 & 0.316 \\
\hline NA & Nurse aids & 2.438 & 0.589 \\
\hline LN & Licensed nurses, including RNs and LPNs & 1.101 & 0.550 \\
\hline LPN & Licensed practical nurses & 0.759 & 0.399 \\
\hline \multicolumn{4}{|l|}{ Quality } \\
\hline DEF1 & Count of total deficiencies & 7.366 & 6.214 \\
\hline DEF2 & Summed scores of total deficiency & 41.059 & 43.608 \\
\hline Care & Count of deficiencies related to quality of care & 4.344 & 3.544 \\
\hline Life & Count of deficiencies related to quality of life & 2.050 & 2.136 \\
\hline Other & Count of other deficiencies & 0.499 & 0.787 \\
\hline Pressure Sores & Fraction of residents with pressure sores & 0.073 & 0.056 \\
\hline Contractures & Fraction of residents with contractures & 0.330 & 0.234 \\
\hline \multicolumn{4}{|c|}{ Instrumental Variables } \\
\hline DIST_RN & Difference between initial RN staffing level and RN mandate & 0.141 & 0.326 \\
\hline DIST_NA & Difference between initial NA staffing level and NA mandate & -0.298 & 0.665 \\
\hline DIST_RN ${ }^{2}$ & DIST_RN squared & 0.126 & 0.447 \\
\hline DIST_NA ${ }^{2}$ & DIST_NA squared & 0.531 & 0.832 \\
\hline DIST_RN_NA & DIST_RN interact with DIST_NA & 0.011 & 0.323 \\
\hline \multicolumn{4}{|l|}{ Market Controls } \\
\hline Income & County-level average income (log) & 10.259 & 0.211 \\
\hline Elderly & County-level elderly population (log) & 10.639 & 1.847 \\
\hline Medicare Rate & State-level Medicare fee-for-service Part A payment rate & 321.955 & 40.271 \\
\hline Medicaid Rate & State-level Medicaid reimbursement rate & 121.672 & 18.085 \\
\hline Wage Index & CBSA-level (or state-level for non-CBSA areas) wage index & 0.973 & 0.159 \\
\hline
\end{tabular}

Note: The sample includes a total of 3,275 nursing homes used in the main analysis from OSCAR 1999 and 2003. The instrumental variables are based on staffing data from 1996 to 1998. 
Table 3: Main Results Regarding Nurse Staffing and Quality of Care

\begin{tabular}{lcc}
\hline \hline & $(1)$ & $(2)$ \\
\hline$\Delta \mathrm{RN}$ & 0.089 & $0.540^{* * *}$ \\
& $(0.050)$ & $(0.119)$ \\
$\Delta \mathrm{NA}$ & 0.023 & 0.041 \\
& $(0.020)$ & $(0.106)$ \\
$\Delta$ Income (log) & 0.649 & 0.644 \\
& $(0.833)$ & $(0.792)$ \\
$\Delta$ Elderly (log) & -0.014 & 0.006 \\
& $(0.041)$ & $(0.033)$ \\
$\Delta$ Wage Index & 0.207 & 0.142 \\
& $(0.400)$ & $(0.369)$ \\
$\Delta$ Medicare Rate & $0.004 * * *$ & $0.004 * * *$ \\
& $(0.002)$ & $(0.001)$ \\
$\Delta$ Medicaid Rate & -0.006 & -0.005 \\
& $(0.007)$ & $(0.006)$
\end{tabular}

Estimation OLS IV

Notes: Each column presents coefficient estimates from separate regressions of equation (2). Quality is measured using a (negative) logarithm of the count of deficiencies. The instrument variables used include DIST_RN, DIST_NA, DIST_RN ${ }^{2}$, DIST_NA ${ }^{2}$, and DIST_RN_NA. The total number of observations is 3,275 . Standard errors are reported in parentheses. ${ }^{* * *}-\mathrm{p}<.01,{ }^{* *}-\mathrm{p}<$ $.05, *-\mathrm{p}<.10$ 
Table 4: Alternative Quality Measures

\begin{tabular}{ccccccc}
\hline \hline & $(1)$ & $(2)$ & $(3)$ & $(4)$ & $(5)$ & $(6)$ \\
& scores & care & life & Other & bedsores & contractures \\
\hline$\Delta$ RN & $0.688 * * *$ & $0.516^{* * *}$ & $0.438^{* * *}$ & 0.075 & $0.041^{* *}$ & $0.115^{*}$ \\
& $(0.263)$ & $(0.162)$ & $(0.169)$ & $(0.220)$ & $(0.021)$ & $(0.065)$ \\
\multirow{2}{*}{$\Delta$ NA } & -0.052 & -0.015 & 0.136 & 0.104 & 0.007 & -0.053 \\
& $(0.151)$ & $(0.063)$ & $(0.085)$ & $(0.092)$ & $(0.006)$ & $(0.037)$ \\
\hline
\end{tabular}

Notes: Each column presents coefficient estimates from separate regressions of equation (2) using IV. The instrument variables used include DIST_RN, DIST_NA, DIST_RN ${ }^{2}$, DIST_NA ${ }^{2}$, and DIST_RN_NA. Column 1 uses a (negative) logarithm of the score measure of deficiencies that accounts for differentials in the scope and severity of each deficiency; columns 2 to 4 consider a logarithm of the count of deficiencies of three distinct categories: quality of care, quality of life, and other; columns 5 and 6 use the fraction of residents with bedsores and the fraction with contractures, respectively. The total number of observations is 3,275 . Standard errors are reported in parentheses. ${ }^{* * *}-\mathrm{p}<.01,{ }^{* *}-\mathrm{p}<.05,{ }^{*}-\mathrm{p}<.10$. 
Table 5: Estimation with the Inclusion of LPN

\begin{tabular}{lcc}
\hline \hline & $(1)$ & $(2)$ \\
\hline$\Delta \mathrm{RN}$ & $0.571^{* *}$ & \\
& $(0.247)$ & \\
$\Delta \mathrm{LPN}$ & 1.003 & \\
& $(0.725)$ & \\
$\Delta \mathrm{LN}$ & & $0.694^{* * *}$ \\
& & $(0.141)$ \\
$\Delta \mathrm{NA}$ & -0.058 & -0.036 \\
& $(0.149)$ & $(0.116)$ \\
\hline
\end{tabular}

Notes: Each column presents coefficient estimates from separate regressions of an alternative to equation (2) where we also consider LPN. All columns use a (negative) logarithm of the count of deficiencies as their measure of quality. The total number of observations is 3,186 , which is smaller than the sample size of our main estimation due to missing values of LPN for some observations. Standard errors are reported in parentheses. $* * *-\mathrm{p}<.01, * *-\mathrm{p}<.05, *-\mathrm{p}<.10$. 
Table 6: Robustness Tests

\begin{tabular}{|c|c|c|c|c|c|c|c|}
\hline & (1) & $(2)$ & (3) & (4) & (5) & (6) & (7) \\
\hline$\Delta \mathrm{RN}$ & $\begin{array}{c}0.558 * * \\
(0.262)\end{array}$ & $\begin{array}{r}0.540 * * * \\
(0.119)\end{array}$ & $\begin{array}{r}0.591 * * * \\
(0.156)\end{array}$ & $\begin{array}{r}0.648 * * * \\
(0.239)\end{array}$ & $\begin{array}{r}0.511^{* * * *} \\
(0.054)\end{array}$ & $\begin{array}{r}0.542 * * * \\
(0.164)\end{array}$ & $\begin{array}{r}0.539 * * * \\
(0.114)\end{array}$ \\
\hline$\Delta \mathrm{NA}$ & $\begin{array}{r}-0.124 \\
(0.286)\end{array}$ & $\begin{array}{r}0.041 \\
(0.106)\end{array}$ & $\begin{array}{r}0.000 \\
(0.058)\end{array}$ & $\begin{array}{r}0.055 \\
(0.119)\end{array}$ & $\begin{array}{r}0.165 \\
(0.126)\end{array}$ & $\begin{array}{r}0.048 \\
(0.162)\end{array}$ & $\begin{array}{r}0.039 \\
(0.103)\end{array}$ \\
\hline$\Delta \mathrm{RN}^{2}$ & $\begin{array}{r}-0.015 \\
(0.267) \\
0.035 \\
(0.081)\end{array}$ & & & & & & \\
\hline Observations & 3,275 & 3,275 & 2,880 & 2,914 & 2,208 & 2,480 & 4,769 \\
\hline \multicolumn{8}{|c|}{$\begin{array}{l}\text { Notes: All columns use a (negative) logarithm of the count of total deficiencies as their measure of } \\
\text { quality. Column } 1 \text { allows for a nonlinear relationship between nurse staffing and quality of care; column } \\
2 \text { adds a control variable for tort legislation changes; columns } 3 \text { and } 4 \text { consider choice of different years } \\
\text { for analysis, where column } 3 \text { uses the year } 1998 \text { to calculate instrumental variables, and column } 4 \text { uses } \\
\text { the year } 1997 \text { for the calculation of instrumental variables and } 1998 \text { and } 2002 \text { as the years before and } \\
\text { after policy changes; columns } 5 \text { and } 7 \text { consider choice of states, where column } 5 \text { drops Florida, Iowa, } \\
\text { and Maine, column } 6 \text { drops Arkansas, Delaware, and Florida, and column } 7 \text { adds observations from a } \\
\text { set of } 11 \text { control states. Standard errors are reported in parentheses. } * * *-p<.01 \text {, ** }-\mathrm{p}<.05 \text {, * - p }< \\
.10 \text {. }\end{array}$} \\
\hline
\end{tabular}


Table 7: The Effect of Staffing Mandates on the Use of Material-Intensive Care and Staffing Levels

\begin{tabular}{|c|c|c|c|c|}
\hline Panel A: & $\begin{array}{c}(1) \\
\text { Physical } \\
\text { Restraints } \\
\end{array}$ & $\begin{array}{c}\text { (2) } \\
\text { Catheters }\end{array}$ & $\begin{array}{c}\text { (3) } \\
\text { Physical } \\
\text { Restraints }\end{array}$ & $\begin{array}{c}\text { (4) } \\
\text { Catheters }\end{array}$ \\
\hline $\mathrm{RN}$ & $\begin{array}{l}-0.032 \\
(0.017)\end{array}$ & $\begin{array}{l}-0.002 \\
(0.002)\end{array}$ & $\begin{array}{l}-0.029 * \\
(0.015)\end{array}$ & $\begin{array}{l}-0.001 \\
(0.004)\end{array}$ \\
\hline RN_binding & $\begin{array}{c}0.011 \\
(0.008)\end{array}$ & $\begin{array}{l}-0.003 \\
(0.007)\end{array}$ & $\begin{array}{c}0.010 \\
(0.008)\end{array}$ & $\begin{array}{l}-0.003 \\
(0.006)\end{array}$ \\
\hline NA & $\begin{array}{c}0.003 \\
(0.004)\end{array}$ & $\begin{array}{l}-0.000 \\
(0.001)\end{array}$ & $\begin{array}{c}0.003 \\
(0.005)\end{array}$ & $\begin{array}{l}-0.001 \\
(0.001)\end{array}$ \\
\hline NA_binding & $\begin{array}{c}0.000 \\
(0.003)\end{array}$ & $\begin{array}{c}0.001 \\
(0.001)\end{array}$ & $\begin{array}{c}0.000 \\
(0.003)\end{array}$ & $\begin{array}{c}0.001 \\
(0.001)\end{array}$ \\
\hline F-stat: $\mathrm{RN}+\mathrm{RN} \_$binding $=0$ & 1.09 & 0.77 & 0.54 & 0.25 \\
\hline F-stat: NA+NA_binding $=0$ & 0.37 & 1.18 & 0.26 & 0.27 \\
\hline With Control States & No & No & Yes & Yes \\
\hline Number of Observations & 19,002 & 19,002 & 27,329 & 27,329 \\
\hline Panel B: & $\begin{array}{c}(5) \\
\text { RN Staffing }\end{array}$ & $\begin{array}{c}(6) \\
\text { NA Staffing }\end{array}$ & $\begin{array}{c}(7) \\
\text { RN Staffing }\end{array}$ & $\begin{array}{c}(8) \\
\text { NA Staffing }\end{array}$ \\
\hline $\mathrm{RN}$ & $\begin{array}{c}-0.208^{* * *} \\
(0.031)\end{array}$ & $\begin{array}{l}-0.174^{*} \\
(0.098)\end{array}$ & $\begin{array}{c}-0.220 * * * \\
(0.048)\end{array}$ & $\begin{array}{l}-0.148 \\
(0.131)\end{array}$ \\
\hline RN_binding & $\begin{array}{c}0.434^{* * *} \\
(0.046)\end{array}$ & $\begin{array}{c}0.268 * * \\
(0.133)\end{array}$ & $\begin{array}{c}0.432 * * * \\
(0.046)\end{array}$ & $\begin{array}{c}0.267 * * \\
(0.135)\end{array}$ \\
\hline NA & $\begin{array}{l}-0.006 \\
(0.008)\end{array}$ & $\begin{array}{c}0.049 \\
(0.031)\end{array}$ & $\begin{array}{l}-0.005 \\
(0.010)\end{array}$ & $\begin{array}{c}0.044 \\
(0.032)\end{array}$ \\
\hline NA_binding & $\begin{array}{c}0.012 * * \\
(0.006)\end{array}$ & $\begin{array}{l}0.090^{*} \\
(0.048)\end{array}$ & $\begin{array}{c}0.011 * * \\
(0.006)\end{array}$ & $\begin{array}{l}0.095^{*} \\
(0.049)\end{array}$ \\
\hline F-stat: $\mathrm{RN}+\mathrm{RN}$ _binding $=0$ & $62.58 * * *$ & 0.21 & $21.12 * * *$ & 0.25 \\
\hline F-stat: NA+NA_binding=0 & 3.12 & $17.57 * * *$ & 1.27 & $18.72 * * *$ \\
\hline $\begin{array}{l}\text { With Control States } \\
\text { Number of Observations }\end{array}$ & $\begin{array}{c}\text { No } \\
22,746\end{array}$ & $\begin{array}{c}\text { No } \\
22,746\end{array}$ & $\begin{array}{c}\text { Yes } \\
32,672\end{array}$ & $\begin{array}{c}\text { Yes } \\
32,672\end{array}$ \\
\hline
\end{tabular}

Notes: Panel A (B) reports results for regressions of the use of material-intensive care (staffing levels) on regulatory staffing mandates, controlling for market characteristics, time fixed effects, and nursing home fixed effects. The number of observations varies across regressions due to data missing for the outcome variables of interest. The time period covered ranges from 1997 to 2003. RN_binding is the interaction of RN mandates and a dummy variable denoting if a nursing home's initial RN staffing level was below the newly imposed mandates. NA_binding is the interaction of NA mandates and a dummy variable for a nursing home's compliance status for NA mandates. Standard errors, clustering at the state level, are reported in parenthesis. $* * *-\mathrm{p}<.01, * *-\mathrm{p}<.05, *-\mathrm{p}<.10$. 